\title{
Can output explain the predictability and volatility of stock returns?
}

\author{
Rosa Rodríguez ${ }^{\mathrm{a}}$, Fernando Restoy ${ }^{\mathrm{b}}$, J. Ignacio Peña ${ }^{\mathrm{c}, *}$ \\ a Universidad Europea de Madrid, Departamento de Matemáticas, Villav, Odón 28670-Madrid, Spain \\ ${ }^{\mathrm{b}}$ Banco de España and CEPR, Servicio de Estudios, C/Alcalá 50, 28014-Madrid, Spain \\ c Universidad Carlos III de Madrid, Dpto. de Economí a de la Empresa, Getafe, 28903-Madrid, Spain
}

\begin{abstract}
This paper examines whether a general equilibrium asset pricing model can explain two important empirical regularities of asset returns, extensively documented in the literature: (i) returns can be predicted by a set of macro variables, and (ii) returns are very volatile. We derive a closed-form solution for the equilibrium asset pricing model that relates asset returns to output by using an approximate method proposed by Campbell (Am. Econ. Rev. 83 (1993) 487) and Restoy and Weil (W.P. NBER, No. 6611 (1998)). We obtain evidence on eight OECD economies using both quarterly and annual observations. Equilibrium models seem to fin fewer difficultie in explaining the volatility of returns than their predictability for general output processes. In the case of the US, the observed predictability and volatility of asset returns, for annual frequencies, are broadly compatible with the predictions of equilibrium models for a reasonable specificatio of preferences. (c) 2002 Elsevier Science Ltd. All rights reserved.
\end{abstract}

JEL classification G12; G14

Keywords: Generalized isoelastic preferences; Asset returns; Real activity; Volatility

\footnotetext{
* Corresponding author.

E-mail address: ypenya@eco.uc3m.es (J.I. Peña).
} 


\section{Introduction}

The empirical literature on f nancial markets has provided extensive evidence on two main regularities: (i) (excess) returns are predictable (in the sense that their conditional mean is not a constant) (Fama, 1981, 1990; Cozier and Rahman, 1988; Fama and French, 1988; Balvers et al., 1990; Barro, 1990; Bondt and Bange, 1991; Chen, 1991; Malliriaris and Urutia, 1991; Bong-Soo, 1992; Marathe and Shawky, 1994; Gallinger, 1994; Hawawini and Keim, 1994; Peiró, 1996; Lee, 1996) and (ii) aggregate stock prices seems to be far more volatile than measures of expected future dividends (LeRoy and Porter, 1981; Shiller, 1981). As it is well known, although both empirical regularities have been often used to challenge the market eff ciency paradigm, they do not necessarily contradict agents' rationality to the extent they are risk averse. Thus, Balvers et al. (1990) have shown that equilibrium stock returns in a log-utility representative agent framework will be predictable if output is predictable. Similarly, Grossman and Shiller (1981), have shown that if a economy's representative agent is suff ciently risk averse, equilibrium stock prices could possibly be more volatile than future (constantly) discounted dividends. However, as pointed out by Campbell and Shiller (1988), the predictability and the excess volatility of stock returns are not separate issues. Indeed, excess volatility of asset prices -with respect to the expected sum of future discounted dividends- directly implies some form of forecastability of future returns. An interesting issue is, then, whether fundamentals can simultaneously explain, in equilibrium, the observed volatility and forecastability of asset returns.

Despite its relevance, there have been so far very few attempts to study this question. One exception is Kandel and Stambaugh (1991), who calibrate numerically the implications of an intertemporal asset pricing model with generalized isoelastic preferences (Epstein and Zin, 1989; Weil, 1989) on the autocorrelation and volatility of asset returns when consumption follows a simple univariate Markov process. One obstacle to address this issue in a more general setting, is the diff culty in obtaining closed-form solutions of equilibrium asset pricing models that could permit returns to be expressed explicitly in terms of economic variables when agents are risk-averse.

In this paper we use a simple framework to study the ability of equilibrium asset pricing models to explain the predictability and volatility of returns for a general specif cation of preferences and of the output process. The analysis makes use of the "approximation technology" developed in Campbell (1993) and Restoy and Weil (1998) to obtain approximate closed-form solutions that relate asset returns to output. The implications of the model are tested using data on eight industrialized countries.

The organization of the paper is as follows. In Section 2 we study whether macroeconomic variables can be used to predict stock returns in a sample of eight OECD economies and compare the volatility of returns with that of the variables usually considered as fundamentals of asset prices. Section 3 describes the model and its implications for the predictability and volatility of returns. Section 4 tests the implications of the model for all eight countries following a multivariate approach. Finally, Section 5 contains some concluding remarks. 


\section{Stylized facts}

In this section we provide evidence on the predictability and volatility of stock returns for the US, the UK, Canada, France, Germany, Italy, Japan and Spain. We use quarterly and annual data on returns, dividend yields, output (industrial production) and three-month interest rates from 1970 to 1996.

\subsection{Predictability of returns}

We study the predictable time variation in stock returns by regressing real stock returns on the explanatory variables usually employed in the literature to document the predictability of returns. These variables are the one-period lagged stock return $\left(r_{t}\right)$, the lagged dividend yield ${ }^{1}\left(d y_{t}\right)$, the lagged growth rate of aggregate output ${ }^{2}$ $\left(y_{t}\right)$ and short-term interest rates $\left(r e_{t}\right)$. The latter variable is detrended by subtracting one-year moving average. ${ }^{3}$

The stock market indexes and the gross dividend yields were obtained from Morgan Stanley Capital International (MSCI). Short-term interest rates, output and CPI inf ation are taken from the OECD data base. The latter is used to convert nominal returns into real ones.

Table 1 presents the results of the regressions. For each regression the table reports the estimated coeff cients, the adjusted coeff cient of determination, and the signif cance level for a Wald test of the hypothesis that all coeff cients are zero. Heteroskedasticity-consistent covariance matrices are used.

With quarterly data, there is some (weak) evidence of stock returns' predictability only in the cases of Italy, United Kingdom, and United States. ${ }^{4}$ The forecasting power of each of the right hand side variables generally varies from country to country. In all cases, however, the model explains only a very limited part of the variability of returns.

When we use annual observations, the forecasting variables are jointly signif cant at reasonable levels of signif cance only for the US and the UK. In those two cases the forecasting power of the right hand side variables is, however, remarkable. The estimated model explains $16 \%$ of the variability of returns for the US and $27 \%$ for the UK. Thus, the forecastability of stock returns seems to increase with the time interval over which returns are measured. This result is consistent with those of Campbell and Shiller (1988) and Fama and French (1988). The sign pattern for dividend yields and interest rates is stable across time measurement intervals,

\footnotetext{
${ }^{1}$ Price-earnings ratios have been found to predict returns in the US (Campbell and Shiller, 1988; Fama and French, 1988).

2 This variable is used to forecast stock returns in Marathe and Shawky (1994), Balvers et al. (1990) and Chen (1991).

3 This variable is also used to forecast stock returns in Campbell (1990).

${ }_{4}$ The US results reported for both frequencies use the S\&P500 index, and the dividend yield of this index (Citibase) from 1947 to 1996.
} 


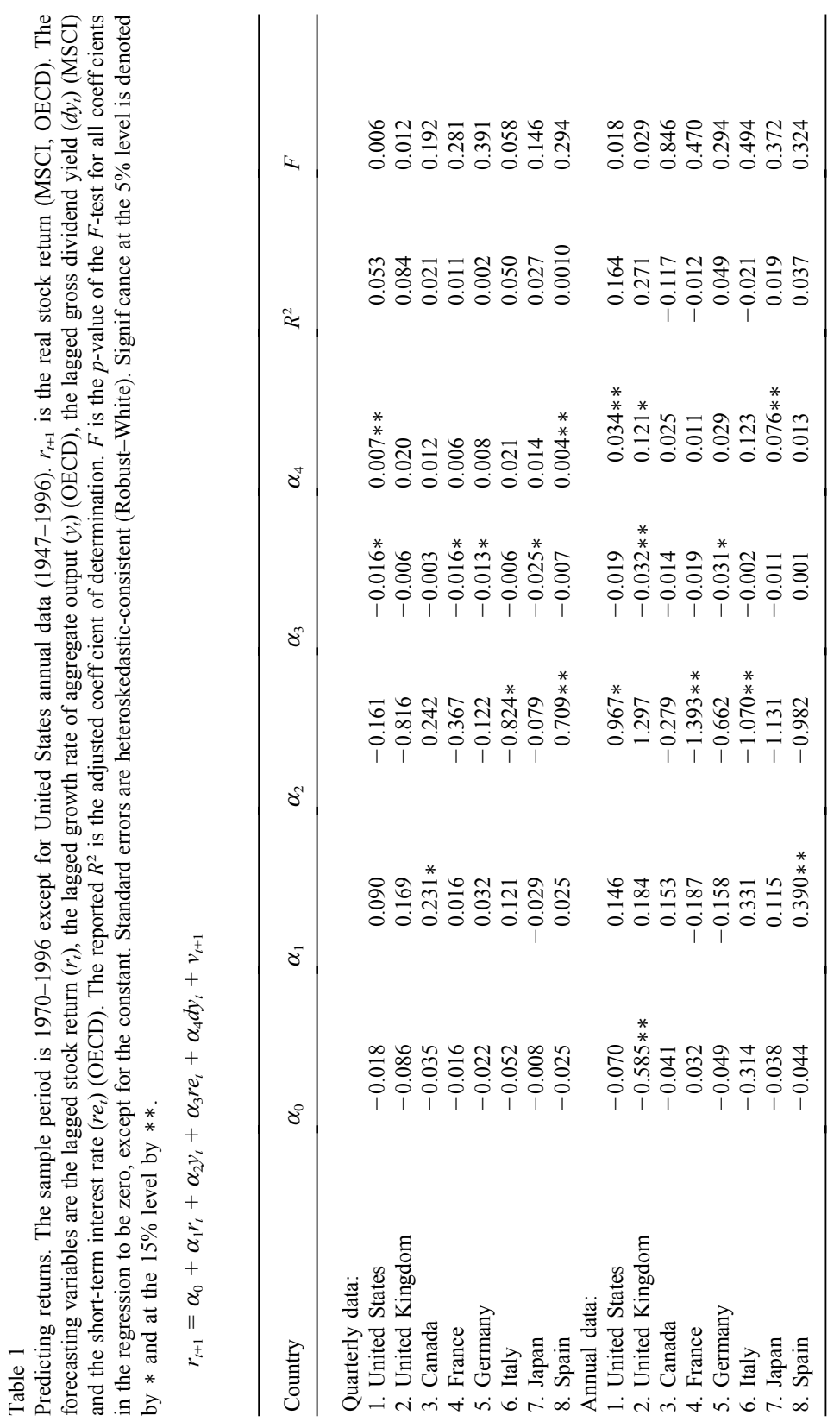


although there are some shifts in the magnitude and statistical signif cance of the coeff cients.

Therefore, we have found some empirical evidence on the ability of the dividend yield, the growth rate of output, the short-term interest rate and the lagged returns, to forecast stock returns. This forecasting ability is particularly high in the case of the UK and the US and for annual frequencies.

\subsection{Excessive volatility in stock returns}

Variances of the different variables considered are reported in Table 2. This table shows that returns are much more volatile - in all countries - than any of the variables normally used to estimate the stock market fundamentals: interest rates, the dividend yield or output growth. The highest volatility of stock returns is found in Italy, Spain and the UK.

In the following sections we assess the ability of equilibrium asset pricing models to explain both stylized facts illustrated in this section; namely the predictability and (excess) volatility of stock returns.

Table 2

Variances $^{\mathrm{a}}$

\begin{tabular}{lllll}
\hline Country & $\operatorname{var}\left(r_{t}\right)$ & $\operatorname{var}\left(y_{t}\right)$ & $\operatorname{var}\left(d y_{t}\right)$ & $\operatorname{var}\left(r e_{t}\right)$ \\
\hline Annual data: & & & & \\
1. United States & 2.836 & 0.322 & 0.013 & 0.026 \\
2. United Kingdom & 7.311 & 0.178 & 0.025 & 0.086 \\
3. Canada & 2.597 & 0.337 & 0.006 & 0.053 \\
4. France & 6.181 & 0.157 & 0.028 & 0.067 \\
5. Germany & 5.411 & 0.218 & 0.012 & 0.055 \\
6. Italy & 8.793 & 0.513 & 0.006 & 0.110 \\
7. Japan & 6.610 & 0.381 & 0.012 & 0.045 \\
8. Spain & 7.150 & 0.278 & 0.158 & 0.133 \\
Quarterly data: & & & & \\
1. United States & 0.528 & 0.053 & 0.013 & 0.007 \\
2. United Kingdom & 1.150 & 0.039 & 0.016 & 0.017 \\
3. Canada & 0.658 & 0.041 & 0.006 & 0.015 \\
4. France & 1.254 & 0.029 & 0.028 & 0.016 \\
5. Germany & 0.897 & 0.072 & 0.011 & 0.013 \\
6. Italy & 1.774 & 0.164 & 0.006 & 0.018 \\
7. Japan & 1.154 & 0.045 & 0.014 & 0.009 \\
8. Spain & 1.456 & 0.079 & 0.133 & 0.032 \\
8 & & &
\end{tabular}

a See Table 1 for description of variables. Variances are multiplied by 100 . 


\section{The model}

\subsection{The economy}

This section presents a general equilibrium discrete-time model relating asset prices to real macroeconomic variables. The economy is similar, except for the agent's preferences, to Lucas (1978) and Mehra and Prescott (1985). Preferences are of a generalized isoelastic form (GIP) as proposed by Epstein and Zin (1989) and Weil (1989).

Take one perishable consumption good, a fruit, which is produced by non-reproducible identical trees whose number is normalized, without loss of generality, to be equal to the size of the constant population. Let $Y_{t}$ denote the number of fruits falling from a tree at time $t$. $Y_{t+1}$ then follows the process

$$
Y_{t+1}=Y_{t} \mathrm{e}^{\psi_{t+1}},
$$

where the growth rate of output $\psi_{t+1}$, is a Markovian random variable.

The economy is inhabited by many identical inf nitely-lived consumers. Let $P_{t}$, $N_{t}$ and $C_{t}$ denote, respectively, the fruit price, the number of trees (shares) and consumption of a representative agent (at period $t$ ). The one-period budget constraint faced by the representative consumer is

$$
C_{t}+P_{t} N_{t+1}=\left(P_{t}+Y_{t}\right) N_{t} \quad t \geq 0,
$$

with $N_{0}>0$. Let $R_{t+1}=\frac{P_{t+1}+Y_{t+1}}{P_{t}}$ be the one-period real rate of return on the tree (the wealth portfolio), and $W_{t}=\left(P_{t}+Y_{t}\right) N_{t}$ the wealth that the agent possesses at time $t$. The budget constraint (2) can be rewritten as

$$
W_{t+1}=R_{t+1}\left(W_{t}-C_{t}\right) \text {. }
$$

The identical consumers have generalized isoelastic preferences with constant elasticity of intertemporal substitution $\left(\frac{1}{\rho}\right)$ and constant coeff cient of relative risk aver$\operatorname{sion}(\gamma) .^{5}$

Epstein and Zin (1989) have shown that for any asset $j$ with gross rate of return $R_{j, t+1}$ between dates $t$ and $t+1$ the following Euler equation must be satisf ed:

$$
E_{t}\left[\beta^{\theta}\left(\frac{C_{t+1}}{C_{t}}\right)^{-\rho \theta} R_{t+1}^{\theta-1} R_{j, t+1}\right]=1,
$$

\footnotetext{
5 The advantage of this specif cation for the preferences lies in its ability to generalize, in a nonexpected utility framework, the commonly used time-additive isoelastic expected utility specif cation. Thus, Epstein-Zin (1989) utility allows for an independent parametrization of attitudes toward risk and attitudes toward intertemporal substitution.
} 
where $\theta$ is equal to $\frac{1-\gamma}{1-\rho}$, the operator $E_{t}$ denotes mathematical expectation conditional on information available at $t$, and $\beta$ is the time-preference parameter.

Naturally, equilibrium in this endowment economy implies $C_{t}=Y_{t}$. To make the link between output and the rate of return on wealth explicit, one must go beyond the Euler equation and use the information provided by the budget constraint. This objective requires that we circumvent the diff culty that budget constraints are multiplicative in consumption (output) and the rate of return on wealth.

\subsection{Linear approximation to the equilibrium solution}

Campbell (1993) and Restoy and Weil (1998) have derived a method of obtaining approximate closed-form solutions to the problem above. That solution is useful to us as it allows the predictability and volatility of asset returns to be related to those of their underlying (real) fundamentals.

Following Restoy and Weil (1998) the non-linear budget constraint can be approximated by this log-linear expression

$$
r_{t+1} \approx y_{t+1}-a_{t+1}+\frac{1}{\delta} a_{t}-k
$$

where $y_{t+1}$ denotes the growth rate of aggregate output, $a_{t}$ is the log of the consumption wealth ratio and $k$ and $\delta(0<\delta<1)$ are two linearization constants.

In the case where output growth is conditionally homoskedastic, Restoy and Weil (1998) demonstrate that the rate of return of the market portfolio in equilibrium can be approximately written as

$$
r_{t+1}=\mu+\rho y_{t+1}+(1-\rho) S_{t+1} \sum_{j=0}^{\infty} \delta^{j} y_{t+j+1},
$$

where $S_{t+1}$ is the innovation operator (i.e. $S_{t+1} x_{t+1}=E_{t+1} x_{t+1}-E_{t} x_{t+1}$ ).

Expression (6) makes it clear that both the frst and second-order moments of aggregate returns depend mainly on the elasticity of intertemporal substitution. The coeff cient of relative risk aversion does not directly appear in the expression above although it is embedded in the discount factor, $\delta$.

As shown by Weil (1989) the equity premium in this model depends mainly on the coeff cient of relative risk aversion. Therefore, we can be sure that choosing $\rho$ to match the predictability and volatility of returns does not affect the extent to which the model is able to solve the equity premium puzzle. ${ }^{6}$

\footnotetext{
${ }^{6}$ Kandel and Stambaugh (1991) obtained that a coeff cient of relative risk aversion of around 29 suff ces to match the observed equity premium. Since Mehra and Presscot (1985), it has been normally considered that such a risk aversion was too high to be realistic. However, Weil (1992), making use of the results by Kimball (1990), suggests that such a high coeff cient is consistent with moderately riskaverse agents when markets are incomplete.
} 


\subsection{Predictability of returns and output}

Eq. (6) specif es that the log stock return in period $t+1$ is a weighted combination (with weights $\rho$ and $(1-\rho)$ ) of the current growth rate of aggregate output in that period and changes in the expected growth rate of output produced between $t$ and $t+1$. Furthermore, the parameter that governs the output-returns (or consumptionreturns) relationship is the elasticity of intertemporal substitution. The coeff cient of relative risk aversion $(\gamma)$ affects only the constant term $(\mu)$ in Eq. (6) and the discount term $(\delta)$.

Taking conditional expectations of both sides in (6) we fnd that: ${ }^{7}$

$$
E_{t}\left(r_{t+1}\right)=\mu+\rho E_{t}\left(y_{t+1}\right) .
$$

Therefore, the model implies that returns will be predictable to the extent the output is predictable, and by the same variables that help to predict output, if any.

In our output-returns relationship, two special cases are worth noting:

- If $\rho=1$, Eqs. (6) and (7) become

$$
\begin{aligned}
& r_{t+1}=-\ln \beta+y_{t+1}, \\
& E_{t}\left(r_{t+1}\right)=m+E_{t}\left(y_{t+1}\right) .
\end{aligned}
$$

Those expressions are equivalent to those obtained by Balvers et al. (1990) using logarithmic expected-utility preferences.

- If $\rho \neq 1$, the right hand side of Eq. (6) takes different expressions according to the process followed by the growth rate of aggregate output. For example, we can derive returns when output growth follows a general stationary ARIMA process (see Appendix A) by making use of its MA representation. Then, if $y_{t+1}$ follows an $\mathrm{AR}(1)$ process

$$
y_{t+1}=\phi y_{t}+\varepsilon_{t+1}^{y},
$$

Eq. (6) becomes

$$
r_{t+1}=\mu+\rho y_{t+1}+\frac{(1-\rho)}{(1-\delta \phi)} \varepsilon_{t+1}^{v},
$$

and

$$
E_{t}\left(r_{t+1}\right)=\mu+\phi \rho y_{t} .
$$

Then, if output follows an AR(1) process, it is legitimate to use one-period lagged output to predict returns. This is the approach taken in Marathe and Shawky (1994).

${ }^{7}$ Since the conditional expectations operator satisf es $E_{j} E_{k}=E_{\min (j, k)}$ it follows that for $m \geq 1$,

$$
E_{t+1-m} S_{t+1} y_{t+1+k}=E_{t+1-m}\left(E_{t+1} y_{t+1+k}-E_{t} y_{t+1+k}\right)=E_{t+1-m} y_{t+1+k}-E_{t+1-m} y_{t+1+k}=0 .
$$


Therefore, the proposed approach permits the predictability of stock returns to be related to predictability of output for a general specif cation of preferences and of the process followed by output.

\subsection{General volatility bound}

Subtracting (7) from (6) the model implies that innovations in returns are related to innovations in output by the expression:

$$
S_{t+1} r_{t+1}=S_{t+1} y_{t+1}+(1-\rho) S_{t+1} \sum_{j=1}^{\infty} \delta^{j} y_{t+j+1} .
$$

Therefore, the volatility of stock returns should be completely explained by the volatility of realized and expected output. In principle, that relationship depends on the conditional distribution of output. However, we can fnd an upper bound for the variance of $S_{t+1} r_{t+1}$ for a given variance of $y_{t+1}$.

We can write $y_{t+1}$ as its unconditional expectation plus the sum of its past innovations: ${ }^{8}$

$$
y_{t+1}=E(y)+\sum_{j=0}^{\infty} S_{t+1-j} y_{t+1} .
$$

Since $y_{t+1}$ is stationary, it holds that $\operatorname{var}\left(S_{t+1-j} y_{t+1}\right)=\operatorname{var}\left(S_{t+1} y_{t+1+j}\right)=$ $\sigma_{j}^{2}$ independent of $t .^{9}$ Therefore, since innovations are serially uncorrelated, we know from (14) that the variance of the sum is the sum of variances:

$$
\operatorname{var}\left(y_{t+1}\right)=\sum_{j=0}^{\infty} \operatorname{var}\left(S_{t+1-j} y_{t+1}\right)=\sum_{j=0}^{\infty} \sigma_{j}^{2}
$$

In expression (13) all innovations are realized at the same moment in time. So, we cannot state that the variance of the sum is the sum of the variances since contemporaneous innovations may be correlated. In fact, for a given $\sigma_{0}^{2}, \sigma_{1}^{2} \ldots$, the maximum variance of the summation term in (14) occurs when the elements in the sum are perfectly positively correlated. This means then that $S_{t+1} y_{t+1+j}=\frac{\sigma_{j}}{\sigma_{0}} S_{t+1} y_{t+1}$. Substituting this into (14) implies $\hat{y}_{t+1}=\sum_{j=0}^{\infty} \frac{\sigma_{j}}{\sigma_{0}} \varepsilon_{t+1-j}$ where hat denotes a variable

${ }^{8}$ If we regard $E(y)$ as $E_{-\infty}$, then this expression is simply a tautology. It tells us, though, that $y_{t+1}$ are just different linear combinations of the same innovations in output that enter into the linear combination in (13) that determine $S_{t+1} r_{t+1}$. We can thus ask how large $\operatorname{var}\left(S_{t+1} r_{t+1}\right)$ should be for a given $\operatorname{var}\left(y_{t+1}\right)$.

9 We introduce the assumption that $y_{t}$ is jointly stationary with information, which means that the unconditional covariance between $y_{t}$ and $z_{t-k}$, where $z_{t}$ is any information variable (which might be $y_{t}$ itself), depends only on $k$, and not on $t$. It follows that we can write expressions like $\operatorname{var}\left(S_{t+1} y_{t+1+j}\right)$ without a time subscript. (For a more complete explanation see Shiller (1991).) 
minus its mean $\hat{y}_{t+1}=y_{t+1}-E(y)$ and $e_{t+1}=S_{t+1} y_{t+1}$. Thus, if $\operatorname{var}\left(S_{t+1} r_{t+1}\right)$ is to be maximized for a given $\sigma_{0}^{2}, \sigma_{1}^{2}, \ldots$, the output process must be a moving average process in terms of its own innovations.

We can now f nd the maximum possible variance for $S_{t+1} r_{t+1}$ for a given variance of $y_{t+1}$. Since the innovations in (13) are perfectly positively correlated it holds that

$$
\operatorname{var}\left(S_{t+1} r_{t+1}\right)=\left(\sigma_{0}+\sum_{j=1}^{\infty} \delta^{j}(1-\rho) \sigma_{j}\right)^{2}
$$

If we maximize this expression subject to the constraint $\operatorname{var}\left(y_{t+1}\right)=\sum_{j=0}^{\infty} \sigma_{j}^{2}$ with respect to $\sigma_{0}, \sigma_{1}, \ldots$, we obtain the maximum variance of returns by using the expression

$$
\operatorname{var}\left(S_{t+1} r_{t+1}\right)=\left(1+(1-\rho)^{2} \frac{\delta^{2}}{1-\delta^{2}}\right) \operatorname{var}\left(y_{t+1}\right),
$$

which constitutes an upper volatility bound of stock returns. Therefore, for any stationary output process it holds that

$$
\operatorname{var}\left(S_{t+1} r_{t+1}\right) \leq\left(1+(1-\rho)^{2} \frac{\delta^{2}}{1-\delta^{2}}\right) \operatorname{var}\left(y_{t+1}\right) .
$$

This implication of the model will be empirically explored in Section 4 .

\section{Empirical analysis}

Before addressing the empirical exercise it is important to notice the problems in linking theory to data. The model describes an economy with the following characteristics: no trade, complete markets, no corporate sector, no technological change, no investment in capital, no money and no government sector. The data come from a world with open economies, incomplete markets, corporate sectors, important technological change, investments in capital, money and government sectors. Therefore, we should not attempt to explain all features of the data with such a stylized model. We will rather focus on the extent to which two important stylized facts (predictability, volatility) are compatible with standard equilibrium asset pricing models.

In order to test the ability of the model to explain the predictability and volatility of asset returns we proceed as follows. We f rst study if the evidence on predictability of asset returns is consistent with Eq. (7). Second, we check if the volatility of asset returns is consistent with that predicted by the model and the volatility bound obtained in Section 3. We then test if the model is able to match both the predictability and volatility of asset returns for an economically meaningful specif cation of preferences. Before we proceed to address those issues directly we need to specify 
an empirical model that allows the estimation of the conditional mean and variance of the relevant variables. Rather than rely on a specif c theoretical model, we assume that expectations are generated by a vector autoregression (VAR).

\subsection{A model for output and returns}

We will def ne a vector $z$ with four elements, the frst of which is the real stock return. The second element in the vector is the growth rate of output. The remaining elements are the dividend yield and the (detrended) short-term interest rate. We then assume that the vector $z_{t+1}$ follows a frst-order VAR: ${ }^{10}$

$$
z_{t+1}=\alpha+A z_{t}+w_{t+1} .
$$

Next, we def ne a four-element vector $i 1$, whose frst element is 1 and whose other elements are all 0 . This vector picks out the real stock return $r_{t+1}$ from the vector $z_{t+1}: r_{t+1}=i 1^{\prime} z_{t+1}$ and $S_{t+1} r_{t+1}=i 1^{\prime} w_{t+1}$. We also def ne a second vector $i 2$ whose second element is 1 and the rest are all 0 to obtain $S_{t+1} y_{t+1}=i 2^{\prime} w_{t+1}$. As the frst-order VAR generates a simple multi-period forecast of future growth rates of aggregate output, we can obtain:

$$
S_{t+1} \sum_{j=0}^{\infty} \delta^{j} y_{t^{+1+j}}=i 2^{\prime} \sum_{j=0}^{\infty} \delta^{\mathrm{j}} A^{j} w_{t+1}=i 2^{\prime}(I-\delta A)^{-1} w_{t+1} .
$$

Since for annual frequencies we have a small number of observations for countries other than the US, we have jointly estimated only the equations corresponding to output and returns in those cases. Equations corresponding to dividend yields and short-term interest rates have been individually estimated. In the rest of the cases (all quarterly estimations and the annual estimation for the US) the whole fourequation VAR has been estimated jointly.

Tables 3 and 4 report the matrix of estimated f rst-order VAR coeff cients and the values of $\rho$ for quarterly and annual data. Standard errors are computed from a heteroskedastic-consistent matrix. Signif cance at the 5\% level is denoted by $*$ and at $15 \%$ level by $* *$. The last two columns of the table report the adjusted coeff cient of determination $R^{2}$ and the joint signif cance level of the VAR forecasting variables.

Notice that Eq. (6) can be seen as a restricted version of the frst equation of the VAR model. All f ve coeff cients in this equation will be determined by the structural parameters $\mu$ and $\rho$ and the VAR coeff cients in the rest of the equations. Similarly, the estimated parameters of the restricted VAR model together with Eq. (19) permit an estimate of the volatility of (model-consistent) returns to be obtained.

${ }^{10}$ The assumption that the VAR is frst-order is not restrictive, since a higher-order VAR can always be expressed as a frst-order form in the manner discussed by Campbell and Shiller (1989). However, when we use the values of the Schwarz (1978) criteria for the choice of the lag length in the VAR, the minimized value of the criterion is always associated with the frst-order system in the quarterly cases. In the annual case there are not suff cient degrees of freedom for the estimation of a higher-order VAR. 
Table 3

First Order Vector Autoregression Model-Quarterly data. This table reports coeff cient estimates for a quarterly 1-lag VAR that includes $r_{t}, y_{t}, r e_{t}$ and $d y_{t}$. The sample period is 1970:1 to 1996:4 except for the US in which is 1947:1 1996:4. The reported $R^{2}$ is the adjusted coeff cient of determination. $F$ is the $p$-value of the $F$-test for coeff cients in the regression to be zero, except for the constant. $\rho$ is the GMM estimate obtained from the restricted VAR model. $\chi_{3}^{2}$ is the $p$-value of the $\chi^{2}$ statistic for the three overidentifying restriction of the model. Standard errors are heteroskedastic-consistent (Robust-White). Signif cance at the $5 \%$ level is denoted by $*$ and at the $15 \%$ level by $* *$

\begin{tabular}{|c|c|c|c|c|c|c|c|}
\hline Country & & $r_{t}$ & $y_{t}$ & $r e_{t}$ & $d y_{t}$ & $R^{2}$ & $\mathrm{~F}$ \\
\hline \multirow[t]{5}{*}{ United States } & $r_{t+1}$ & 0.090 & -0.161 & $-0.016 *$ & $0.007 * *$ & 0.053 & 0.006 \\
\hline & $y_{t+1}$ & $0.093 *$ & $0.363 *$ & -0.002 & -0.001 & 0.229 & 0.000 \\
\hline & $r e_{t+1}$ & 0.819 & $7.845 *$ & $0.350 *$ & -0.042 & 0.206 & 0.000 \\
\hline & $d y_{t+1}$ & -0.125 & 1.597 & $0.072 *$ & $0.967 *$ & 0.925 & 0.000 \\
\hline & $\rho$ & 0.577 & \multicolumn{5}{|c|}{$\chi_{3}^{2}=13.29(0.004)$} \\
\hline \multirow[t]{5}{*}{ United Kingdom } & $r_{t+1}$ & 0.169 & -0.916 & -0.006 & 0.020 & 0.084 & 0.012 \\
\hline & $y_{t+1}$ & -0.004 & -0.048 & 0.001 & $-0.005 *$ & 0.073 & 0.020 \\
\hline & $r e_{t+1}$ & $-2.117 *$ & 2.154 & $0.622 *$ & $-0.135 * *$ & 0.439 & 0.000 \\
\hline & $d y_{t+1}$ & $-1.172 * *$ & 6.555 & 0.035 & $0.829 *$ & 0.701 & 0.000 \\
\hline & $\rho$ & -6.888 & \multicolumn{5}{|c|}{$\chi_{3}^{2}=1.408(0.703)$} \\
\hline \multirow[t]{5}{*}{ Canada } & $r_{t+1}$ & $0.231 *$ & 0.242 & -0.003 & 0.012 & 0.021 & 0.192 \\
\hline & $y_{t+1}$ & $0.043 *$ & $0.434 *$ & $-0.004 *$ & -0.003 & 0.320 & 0.000 \\
\hline & $r e_{t+1}$ & 0.653 & $13.921^{*}$ & $0.546 *$ & -0.051 & 0.363 & 0.000 \\
\hline & $d y_{t+1}$ & -0.544 & -0.798 & 0.036 & $0.889 *$ & 0.817 & 0.000 \\
\hline & $\rho$ & 1.103 & \multicolumn{5}{|c|}{$\chi_{3}^{2}=3.925(0.269)$} \\
\hline \multirow[t]{5}{*}{ France } & $r_{t+1}$ & 0.016 & -0.367 & $-0.016 *$ & 0.006 & 0.011 & 0.281 \\
\hline & $y_{t+1}$ & 0.017 & 0.090 & -0.001 & -0.001 & 0.008 & 0.310 \\
\hline & $r e_{t+1}$ & 0.214 & $11.855 *$ & $0.629 *$ & -0.059 & 0.422 & 0.000 \\
\hline & $d y_{t+1}$ & 0.088 & -0.544 & $0.102 *$ & $0.931 *$ & 0.875 & 0.000 \\
\hline & $\rho$ & 15.730 & \multicolumn{5}{|c|}{$\chi_{3}^{2}=2.429(0.488)$} \\
\hline \multirow[t]{5}{*}{ Germany } & $r_{t+1}$ & 0.032 & -0.122 & $-0.013 *$ & 0.008 & 0.002 & 0.390 \\
\hline & $y_{t+1}$ & $0.038 * *$ & $-0.247 * *$ & 0.002 & $-0.004 * *$ & 0.055 & 0.046 \\
\hline & $r e_{t+1}$ & -0.141 & $5.195 *$ & $0.733 *$ & -0.054 & 0.558 & 0.000 \\
\hline & $d y_{t+1}$ & 0.072 & 0.124 & $0.080 *$ & $0.938 *$ & 0.875 & 0.000 \\
\hline & $\rho$ & -1.194 & \multicolumn{5}{|c|}{$\chi_{3}^{2}=4.780(0.188)$} \\
\hline \multirow[t]{5}{*}{ Italy } & $r_{t+1}$ & 0.121 & $-0.824 *$ & -0.006 & 0.021 & 0.050 & 0.058 \\
\hline & $y_{t+1}$ & $0.055 *$ & $-0.313 *$ & $-0.003 * *$ & 0.001 & 0.097 & 0.007 \\
\hline & $r e_{t+1}$ & $-1.442 * *$ & $10.100 *$ & $0.571 *$ & -0.173 & 0.421 & 0.000 \\
\hline & $d y_{t+1}$ & -0.077 & 1.012 & 0.035 & $0.827 *$ & 0.669 & 0.000 \\
\hline & $\rho$ & $2.452 *$ & \multicolumn{5}{|c|}{$\chi_{3}^{2}=1.274(0.735)$} \\
\hline \multirow[t]{5}{*}{ Japan } & $r_{t+1}$ & -0.029 & -0.079 & $-0.025 *$ & $0.014 * *$ & 0.027 & 0.146 \\
\hline & $y_{t+1}$ & $0.034 * *$ & $0.267 *$ & $-0.004 *$ & 0.000 & 0.151 & 0.000 \\
\hline & $r e_{t+1}$ & -0.128 & $9.113 *$ & $0.823 *$ & -0.014 & 0.673 & 0.000 \\
\hline & $d y_{t+1}$ & 0.033 & -0.444 & $0.038 * *$ & $0.921 *$ & 0.961 & 0.000 \\
\hline & $\rho$ & 2.496 & \multicolumn{5}{|c|}{$\chi_{3}^{2}=3.731(0.291)$} \\
\hline \multirow[t]{5}{*}{ Spain } & $r_{t+1}$ & 0.025 & $0.709 *$ & -0.007 & $0.004 * *$ & 0.010 & 0.294 \\
\hline & $y_{t+1}$ & 0.014 & $-0.184 * *$ & -0.002 & $-0.001 *$ & 0.044 & 0.073 \\
\hline & $r e_{t+1}$ & -1.548 & 7.234 & $0.426 *$ & -0.011 & 0.196 & 0.000 \\
\hline & $d y_{t+1}$ & -0.674 & -3.610 & $0.090 * *$ & $0.961 *$ & 0.938 & 0.000 \\
\hline & $\rho$ & 5.993 & \multicolumn{5}{|c|}{$\chi_{3}^{2}=13.29(0.004)$} \\
\hline
\end{tabular}


Table 4

First order vector autoregression model-annual data. This table reports coeff cient estimates for an annual 1-lag VAR that includes $r_{t}, y_{t}, r e_{t}$ and $d y_{t}$. The sample period is 1970 to 1996 except for United States (1947-1996). The reported $R^{2}$ is the adjusted coeff cient of determination. $F$ is the $p$-value of the $F$-test for coeff cients in the regression to be zero, except for the constant. $\rho$ is the GMM estimate of $\rho$ obtained from the restricted VAR model. $\chi_{3}^{2}$ is the $p$-value of the $\chi^{2}$ statistic for the three overidentifying restriction of the model. Standard errors are heteroskedastic-consistent (Robust-White). Signif cance at the 5\% level is denoted by $*$ and at the $15 \%$ level by $* *$

\begin{tabular}{|c|c|c|c|c|c|c|c|}
\hline Country & & $r_{t}$ & $y_{t}$ & $r e_{t}$ & $d y_{t}$ & $R^{2}$ & $F$ \\
\hline \multirow[t]{5}{*}{ United States } & $r_{t+1}$ & 0.146 & $-0.967 *$ & -0.019 & $0.034 * *$ & 0.164 & 0.018 \\
\hline & $y_{t+1}$ & $0.143 *$ & $-0.268 * *$ & -0.005 & 0.002 & 0.156 & 0.022 \\
\hline & $r e_{t+1}$ & 0.936 & 5.716 & 0.082 & 0.007 & -0.002 & 0.433 \\
\hline & $d y_{t+1}$ & 0.438 & 2.499 & 0.099 & $0.862 *$ & 0.748 & 0.000 \\
\hline & $\rho$ & $2.419 *$ & \multicolumn{2}{|l|}{$\chi_{3}^{2}=4.99(0.171)$} & & & \\
\hline \multirow{5}{*}{$\begin{array}{l}\text { United } \\
\text { Kingdom }\end{array}$} & $r_{t+1}$ & 0.184 & 1.297 & $-0.031 * *$ & $0.120 *$ & 0.271 & 0.029 \\
\hline & $y_{t+1}$ & $0.056 * *$ & 0.056 & $-0.006 *$ & -0.004 & 0.373 & 0.007 \\
\hline & $r e_{t+1}$ & 1.992 & -2.409 & 0.008 & -0.161 & -0.118 & 0.850 \\
\hline & $d y_{t+1}$ & -0.773 & -5.974 & $0.223 * *$ & 0.076 & 0.095 & 0.196 \\
\hline & $\rho$ & 7.715 & $\chi_{3}^{2}=2.13(0.54)$ & & & & \\
\hline \multirow[t]{5}{*}{ Canada } & $r_{t+1}$ & 0.153 & -0.279 & -0.014 & 0.025 & -0.117 & 0.846 \\
\hline & $y_{t+1}$ & $0.107 * *$ & 0.146 & $-0.017 *$ & 0.008 & 0.332 & 0.012 \\
\hline & $r e_{t+1}$ & $6.204 * *$ & $11.641 * *$ & 0.026 & $1.118 * *$ & 0.165 & 0.098 \\
\hline & $d y_{t+1}$ & 0.327 & 1.856 & 0.075 & $0.844 *$ & 0.559 & 0.000 \\
\hline & $\rho$ & 0.342 & \multicolumn{2}{|c|}{$\chi_{3}^{2}=0.985(0.804)$} & & & \\
\hline \multirow[t]{5}{*}{ France } & $r_{t+1}$ & -0.187 & $-1.393 * *$ & -0.019 & 0.011 & -0.012 & 0.470 \\
\hline & $y_{t+1}$ & -0.023 & 0.056 & $-0.011 *$ & 0.001 & 0.414 & 0.003 \\
\hline & $r e_{t+1}$ & $3.360 * *$ & $34.973 *$ & $-0.269 * *$ & 0.291 & 0.379 & 0.006 \\
\hline & $d y_{\mathrm{t}+1}$ & 0.835 & 6.349 & $0.148 * *$ & $0.809 *$ & 0.556 & 0.0002 \\
\hline & $\rho$ & $3.365 * *$ & \multicolumn{2}{|c|}{$\chi_{3}^{2}=3.360(0.339)$} & & & \\
\hline \multirow[t]{5}{*}{ Germany } & $r_{t+1}$ & -0.158 & -0.662 & $-0.031 *$ & 0.029 & 0.049 & 0.294 \\
\hline & $y_{t+1}$ & 0.053 & 0.171 & $-0.012 *$ & 0.001 & 0.399 & 0.004 \\
\hline & $r e_{t+1}$ & 2.945 & $27.007 *$ & -0.102 & 0.549 & 0.118 & 0.159 \\
\hline & $d y_{t+1}$ & 0.676 & $6.793 *$ & $0.121 *$ & $0.819 *$ & 0.609 & 0.001 \\
\hline & $\rho$ & 1.465 & \multicolumn{2}{|c|}{$\chi_{3}^{2}=6.852(0.076)$} & & & \\
\hline \multirow[t]{5}{*}{ Italy } & $r_{t+1}$ & 0.331 & $-1.071 * *$ & -0.002 & 0.123 & -0.020 & 0.494 \\
\hline & $y_{t+1}$ & -0.097 & 0.140 & $-0.014 *$ & 0.004 & 0.376 & 0.008 \\
\hline & $r e_{t+1}$ & 2.183 & 6.110 & -0.202 & 0.830 & -0.036 & 0.546 \\
\hline & $d y_{t+1}$ & $-1.374 *$ & 0.120 & 0.027 & 0.060 & 0.230 & 0.053 \\
\hline & $\rho$ & 1.399 & \multicolumn{2}{|c|}{$\chi_{3}^{2}=4.338(0.227)$} & & & \\
\hline \multirow[t]{5}{*}{ Japan } & $r_{t+1}$ & 0.115 & -1.131 & -0.011 & $0.076 * *$ & 0.019 & 0.372 \\
\hline & $y_{t+1}$ & $0.150 *$ & -0.175 & -0.005 & 0.011 & 0.377 & 0.006 \\
\hline & $r e_{t+1}$ & 1.851 & 21.217 & 0.126 & -0.041 & 0.434 & 0.002 \\
\hline & $d y_{t+1}$ & -0.008 & $2.139 * *$ & 0.026 & $0.680 *$ & 0.761 & 0.000 \\
\hline & $\rho$ & $1.811 * *$ & \multicolumn{2}{|c|}{$\chi_{3}^{2}=3.890(0.273)$} & & & \\
\hline \multirow[t]{5}{*}{ Spain } & $r_{t+1}$ & $-0.391 * *$ & -0.982 & 0.001 & 0.136 & 0.037 & 0.324 \\
\hline & $y_{t+1}$ & -0.010 & 0.086 & $-0.003 * *$ & -0.003 & -0.050 & 0.600 \\
\hline & $r e_{t+1}$ & -5.380 & $27.695 *$ & -0.265 & -0.076 & 0.105 & 0.179 \\
\hline & $d y_{t+1}$ & -2.347 & 0.557 & -0.015 & $0.848 *$ & 0.736 & 0.000 \\
\hline & $\rho$ & $12.798 *$ & \multicolumn{2}{|c|}{$\chi_{3}^{2}=2.621(0.45)$} & & & \\
\hline
\end{tabular}




\subsection{Predictability}

In order to test the extent to which the model is consistent with the observed predictability of asset returns we analyze four implications of the model in Section 3. First we observe whether in those cases in which returns are predictable output is also predictable by the same variables. Second, we test whether in those cases in which returns are not predictable, output is not predictable either. Finally, we study if the restricted VAR model is consistent with the data and whether the estimate of $\rho$ arising from the estimation of the restricted VAR model is reasonable in economic terms.

As far as the frst implication of the model is concerned, we saw in Section 2 that returns are only clearly predictable by lagged returns, dividend yields, output and short-term interest rates in the US and the UK and for annual frequencies. Tables 3 and 4 conf rm that result. Therefore, output can be predicted by the proposed set of variables in the US and the UK for both frequencies in agreement with the model.

The second implication we test is whether output is not predictable in those cases in which returns are not predictable. According to Tables 3 and 4 this implication fails in roughly half of the cases.

Finally, we check whether the restrictions on the VAR model implied by Eq. (7) are empirically plausible. According to the $\chi^{2}$-test reported in Tables 3 and 4 , the restrictions of the model are almost never rejected. A different picture emerges if one focuses on the estimated values of the inverse of the elasticity of intertemporal substitution $(\rho)$. Notably, when we use quarterly data we only f nd signif cant estimates of this parameter for Italy. When we employ annual data, instead, the results are more promising and estimates of $\rho$ are positive and signif cant for the US, France, Japan and Spain. We should bear in mind that, except in the case of US, the number of annual observations is relatively small.

Table 5

Volatility test. This table reports the values of $\rho$ that satisfy the volatility restrictions of the model. The frst column shows the minimum values of the parameter satisfying the volatility bound for a general output process. The second one presents the values of the parameter making volatility of model generated returns equal to the volatility of actual returns for the output process implicit in the VAR model

\begin{tabular}{lllll}
\hline \multirow{2}{*}{ Country } & \multicolumn{2}{l}{ Volatility Bound } & \multicolumn{2}{l}{ VAR model } \\
\cline { 2 - 3 } & Quarterly & Annual & Quarterly & Annual \\
\hline 1. United States & 1.94 & 1.78 & 4.78 & 4.86 \\
2. United Kingdom & 2.62 & 2.59 & 7.28 & 7.46 \\
3. Canada & 2.21 & 1.83 & 4.18 & 2.90 \\
4. France & 3.04 & 2.90 & 13.68 & 7.89 \\
5. Germany & 2.08 & 2.35 & 6.52 & 4.90 \\
6. Italy & 1.98 & 2.24 & 5.84 & 5.40 \\
7. Japan & 2.57 & 2.18 & 7.16 & 5.40 \\
8. Spain & 2.33 & 2.46 & 6.72 & 8.04 \\
\hline
\end{tabular}


Overall, the evidence presented suggests that the model is not generally successful in explaining the conditional mean of stock returns in the countries considered. However, the model is able to provide, at least, an empirically plausible explanation in those cases in which the predictability of returns is more signif cant: the US and $\mathrm{UK}$ - for annual frequencies.

\subsection{Volatility}

In order to test whether the volatility of asset returns is consistent with that predicted by the model, we proceed as follows. First, we obtain the minimum values of the inverse of elasticity of intertemporal substitution that satisfy the general volatility bound of Eq. (18). Second, using the parameters of the VAR-model and Eqs. (6) and (19) we obtain the values of $\rho$ that make volatility of the model-generated returns equal to the volatility of observed returns. For both exercises we use a value of $\delta$ equal to 0.95 . Results are not sensitive to variations in $\delta$ within a plausible range. Table 5 reports the results of both volatility tests.

In the frst exercise, we f nd that the volatility bound is satisf ed in all cases and frequencies for values of $\rho$ between 2 and 3. These results do not contradict the standard excess-volatility literature. Thus, Shiller (1981) and LeRoy and Porter (1981) derive volatility bounds which are only valid under constant discount factors (i.e. $\gamma=\rho=0$ ). West (1988) using a model with time varying expected returns, determined by the consumption-based asset-pricing model, obtain a volatility bound which is only robust to values of the coeff cient of relative risk aversion below one (i.e. $\gamma=\rho \leq 1$ ). ${ }^{11}$ According to our results, it is not surprising that all three articles f nd evidence that implies rejection of the derived volatility conditions, since, within the consumption-based asset-pricing setup, a high value for $\rho$ would be needed for the volatility bound to be suff ciently large. In fact, Grossman and Shiller (1981) were able to match actual and perfect foresight stock price volatilities, within the consumption-based asset-pricing model, for values of the coeff cient of relative risk aversion above four (i.e. $\gamma=\rho>4$ ).

Indeed, we have actually found, in our second exercise, that the parameter $\rho$ (which would coincide with the relative risk aversion parameter in a standard consumption-based asset-pricing model) should be even larger, between 3 and 13, for the volatility of model-derived returns to be similar to that of observed returns. Although, the identif cation of a set of admissible values for the coeff cient of relative risk aversion is diff cult task, it seems hard to justify values as large as the ones required to satisfy the volatility conditions above. However, in our GIP framework, in which the coeff cient of relative risk aversion $(\gamma)$ is independent of the elasticity

\footnotetext{
${ }^{11}$ Campbell and Shiller (1989) using a linearized version of a model with time-varying expected returns to compute a variance ratio of the log dividend price ratio - allowing for the consumption-based assetpricing model with constant relative risk aversion to compute expected returns - do not f nd statistically signif cant estimators of the coeff cient of relative risk aversion parameter.
} 
of intertemporal substitution $\left(\frac{1}{\rho}\right)$, the coeff cient that governs the value of the modelderived volatility is unambiguously the inverse of the elasticity of intertemporal substitution. To the extent that, unlike in the case of risk aversion, a high aversion to intertemporal substitution of consumption is not necessarily unreasonable (see Weil, 1989), the generalization of preferences proposed by Epstein and Zin (1989) and Weil (1989) help explaining the so-called stock market volatility puzzle.

\subsection{Joint test of predictability and volatility}

The empirical exercises we have performed so far yield mixed results on the ability of a relatively standard equilibrium asset pricing model to explain the predictability and volatility of asset returns. In general the model has failed to explain satisfactorily the predictability of asset returns from that of real economic activity in most cases. However, the volatility of asset returns does not seem so big as to be explained by the fundamentals of asset prices. Moreover, using annual data for the US and UK, both the observed predictability and volatility of asset returns can be independently explained by the model for reasonable values of the preference parameters. A logical further step is to analyze the extent to which the model is able to simultaneously explain both features of the data for a single specif cation of preferences.

In this section we report the results of conducting a joint GMM estimation of the conditional mean and the unconditional variance of asset returns as a function of the model parameters $\mu$ and $\rho$. For the conditional mean we use Eq. (7) for which expected output is taken from the estimated VAR model. For the unconditional variance of returns we use Eq. (6) and the innovations of output obtained from the VAR model. We thus obtain three moment equations to estimate two parameters. The f rst two equations correspond to the standard OLS moment equations where the dependent variable is the observed returns and the regressors are a constant and the expected output. The third moment equation refers to the difference between the observed volatility of returns and the one predicted by the model according to Eq. (6). We then have one overidentifying restriction that will be used to test (through a $\chi^{2}$ statistic) the ability of the model to match both the predictability and volatility of returns.

Results are reported in Table 6. Not surprisingly, the model fails to properly $\mathrm{ft}$ both moments of data when quarterly observations are used. Results are less negative when annual observations are employed. In this case, we f nd positive and signif cant estimates of the inverse of the elasticity of intertemporal substitution and values of the $\chi^{2}$ tests that do not generally reject the null. It should be stressed, again, that results with annual data on countries other than the US should be viewed with great caution as they are obtained with few observations. Results on the US are probably more informative as they are obtained with much more degrees of freedom. In the US case, the overidentifying restrictions of the model are not rejected at a $1 \%$ signif cance interval, although more demanding criteria would imply a rejection of the null. The point estimate of $\rho(4.1)$ is close to that required by the model to match 
Table 6

Joint test of predictability and volatility. This table reports the values of $\mu$ and $\rho$ that make the conditional expectation and volatility of the model generated returns equal to the conditional expectation and volatility of the actual returns. Standard errors in parentheses. Signif cance at the $5 \%$ level is denoted by $*$. The chi-square statistic tests the overidentifying restriction of the model

\begin{tabular}{|c|c|c|c|c|c|c|}
\hline \multirow[t]{2}{*}{ Country } & \multicolumn{3}{|l|}{ Quarterly } & \multicolumn{3}{|l|}{ Annual } \\
\hline & $\mu$ & $\rho$ & $\chi_{1}$ & $\mu$ & $\rho$ & $\chi_{1}$ \\
\hline 1. United States & $\begin{array}{l}-0.043 \\
(0.008) *\end{array}$ & $\begin{array}{l}5.188 \\
(0.346) *\end{array}$ & $\begin{array}{l}40.175 \\
(0.0000)\end{array}$ & $\begin{array}{l}-0.124 \\
(0.041) *\end{array}$ & $\begin{array}{l}4.124 \\
(0.774) *\end{array}$ & $\begin{array}{l}7.348 \\
(0.010)\end{array}$ \\
\hline 2. United Kingdom & $\begin{array}{l}-0.028 \\
(0.011) *\end{array}$ & $\begin{array}{l}8.439 \\
(0.403) *\end{array}$ & $\begin{array}{l}4.439 \\
(0.035)\end{array}$ & $\begin{array}{l}-0.097 \\
(0.073)\end{array}$ & $\begin{array}{l}6.608 \\
(2.229) *\end{array}$ & $\begin{array}{l}2.564 \\
(0.109)\end{array}$ \\
\hline 3. Canada & $\begin{array}{l}-0.025 \\
(0.009) *\end{array}$ & $\begin{array}{l}4.867 \\
(0.355) *\end{array}$ & $\begin{array}{l}15.753 \\
(0.0001)\end{array}$ & $\begin{array}{l}-0.037 \\
(0.039)\end{array}$ & $\begin{array}{l}2.922 \\
(0.561) *\end{array}$ & $\begin{array}{l}5.306 \\
(0.021)\end{array}$ \\
\hline 4. France & $\begin{array}{l}-0.051 \\
(0.013) *\end{array}$ & $\begin{array}{l}14.416 \\
(1.385) *\end{array}$ & $\begin{array}{l}9.881 \\
(0.001)\end{array}$ & $\begin{array}{l}-0.024 \\
(0.058)\end{array}$ & $\begin{array}{l}8.651 \\
(1.103) *\end{array}$ & $\begin{array}{l}6.491 \\
(0.011)\end{array}$ \\
\hline 5. Germany & $\begin{array}{l}-0.002 \\
(0.011)\end{array}$ & $\begin{array}{l}5.786 \\
(0.727) *\end{array}$ & $\begin{array}{l}14.174 \\
(0.0001)\end{array}$ & $\begin{array}{l}0.026 \\
(0.052)\end{array}$ & $\begin{array}{l}4.179 \\
(1.294) *\end{array}$ & $\begin{array}{l}5.707 \\
(0.017)\end{array}$ \\
\hline 6. Italy & $\begin{array}{l}-0.019 \\
(0.014)\end{array}$ & $\begin{array}{l}4.116 \\
(0.933) *\end{array}$ & $\begin{array}{l}9.133 \\
(0.002)\end{array}$ & $\begin{array}{l}-0.132 \\
(0.070)\end{array}$ & $\begin{array}{l}3.980 \\
(1.182) *\end{array}$ & $\begin{array}{l}4.578 \\
(0.032)\end{array}$ \\
\hline 7. Japan & $\begin{array}{l}-0.024 \\
(0.016)\end{array}$ & $\begin{array}{l}6.148 \\
(0.951) *\end{array}$ & $\begin{array}{l}15.170 \\
(0.0001)\end{array}$ & $\begin{array}{l}-0.038 \\
(0.067)\end{array}$ & $\begin{array}{l}5.502 \\
(0.917) *\end{array}$ & $\begin{array}{l}4.287 \\
(0.038)\end{array}$ \\
\hline 8. Spain & $\begin{array}{l}-0.038 \\
(0.015)\end{array}$ & $\begin{array}{l}7.109 \\
(0.798)\end{array}$ & $\begin{array}{l}25.931 \\
(0.000)\end{array}$ & $\begin{array}{l}-0.252 \\
(0.075)\end{array}$ & $\begin{array}{l}9.421 \\
(1.146) *\end{array}$ & $\begin{array}{l}9.782 \\
(0.001)\end{array}$ \\
\hline
\end{tabular}

the volatility of returns, and slightly above the one which would match the conditional mean of returns.

On the whole, at least in the case of the US and for annual data, results are relatively supportive of the ability of the equilibrium model studied to replicate the observed predictability and volatility of asset returns.

Since we are using a linear approximation to equilibrium conditions, any rejection of the model could always be attributed to the higher order terms not considered in the empirical test. Nevertheless, this is unlikely as conditional higher order moments of output, which would form the higher order terms in a more accurate approximation, typically show low variability and covariability with the variables that help predicting returns. ${ }^{12}$

\section{Conclusions}

In this paper we have studied the ability of relatively standard equilibrium asset pricing models to explain two important empirical regularities of asset returns inten-

\footnotetext{
${ }^{12}$ As an example, with US annual (quarterly) data, the variability of the square of the conditional mean of returns is 45 (314) times lower than the variability of the conditional mean of returns.
} 
sively documented in the literature: (i) returns can be predicted by a set of macroeconomic variables; and (ii) returns are very volatile. These empirical regularities are relevant because they have been often used to reject market eff ciency.

We use the approximation technology for the solution of intertemporal asset pricing models recently developed by Campbell (1993) in the form suggested by Restoy and Weil (1998). Such approach permits asset returns to be explicitly expressed in terms of real economic variables. This makes it possible to test whether observed and model-generated moments of returns are suff ciently close, by using simple statistical procedures. The approximation technology shows how moments of aggregate returns, unlike those of excess returns, depend mainly on the elasticity of intertemporal substitution and not on agents' risk aversion. This is important, because we can analyze the extent to which the model $\mathrm{f}$ ts the mean and variance of aggregate returns without considering any implication for the equity premium.

Using data form eight OECD economies (quarterly and annual observations) we have found that it is generally easier to explain the volatility of returns than their predictability. Thus, we have shown that for reasonable values of the elasticity of intertemporal substitution, the observed volatility of asset returns can be replicated by that of their real fundamentals according to standard intertemporal asset pricing models. This occurs for all eight countries using both quarterly and annual data.

It is much more diff cult to justify the predictability of asset returns as an implication of equilibrium asset pricing models in most countries. The model is often unable to explain why returns are predictable in those cases in which they are and why they are not predictable in those cases in which they cannot be predicted by standard macro-variables.

Results are more positive for the model in the case of the US when annual data are used. In this case, the observed predictability and volatility of asset returns seems to be broadly compatible with the predictions of equilibrium models for a reasonable specif cation of preferences. This positive result, in the case of the US, as compared with those of other countries is not surprising. The assumptions of the model seem to $\mathrm{ft}$ better to relatively closed economies with large stock markets. In our sample, only the US economy is close to satisfying those assumptions. Moreover, it seems reasonable that equilibrium models behave better when applied to low-frequency data than when they are used to explain short-run movements, if one believes that possible deviations from fundamentals are somewhat transitory.

\section{Appendix A}

Consider that $y_{t+1}$ follows a stationary ARIMA process

$$
\Phi(L) y_{t+1}=\Theta(L) \varepsilon_{t+1}^{y},
$$

where $\Phi(L)$ and $\Theta(L)$ are polynomials in the lag operator $L$ and $\varepsilon_{t+1}$ is a whitenoise (serially uncorrelated and homoskedastic) process. If the process is stationary, the roots of the polynomial $\Phi(L)$ must lie outside the unit circle. The same condition on $\Theta(L)$ guarantees that the moving average is invertible, so that it can be expressed 
in autoregressive form. For example, if we assume that $y_{t+1}$ follows an $\mathrm{MA}(1)$ process with parameter $\theta$, then,

$$
y_{t+1}=(1-\theta L) \varepsilon_{t+1}^{y},
$$

and also,

$$
\begin{aligned}
\left(E_{t+1}-E_{t}\right) y_{t+j+1} & =\varepsilon_{t+1}^{y} & & \text { if } j=0 \\
& =-\theta \varepsilon_{t+1}^{y} & & \text { if } j=1 \\
& =0 & & \text { if } j>1
\end{aligned}
$$

Then, from Eq. (6) in the text,

$$
r_{t+1}=\mu+\rho y_{t+1}+(1-\rho)(1-\delta \theta) \varepsilon_{t+1}^{y} .
$$

It is straightforward to extend this calculation to any moving average process, including the inf nite order case. This is of particular importance since, by the Wold theorem, it can be used to represent a general stationary time series.

Hence, if the production process is

$$
y_{t+1}=\varepsilon_{t+1}^{y}+\sum_{k=1}^{\infty} \theta_{k} \varepsilon_{t^{+1-k}}^{y},
$$

Eq. (6) can be written as

$$
r_{t+1}=\mu+\rho y_{t+1}+(1-\rho)\left(1+\delta \theta_{1}+\delta^{2} \theta_{2}+\ldots\right) \varepsilon_{t+1}^{y} .
$$

This formula gives us a simple rule for evaluating returns from the moving average representation of the output process: simply discount the moving average parameters, and add them up.

\section{References}

Balvers, R., Cosimano, T., McDonald, T., 1990. Predicting stock returns in an eff cient market. J. Fin. 45, 1109-1118.

Barro, R.J., 1990. The stock market and investment. Rev. Fin. Stud. 3, 115-131.

Bondt, W., Bange, M., 1991. The role of the capital markets as leading indicators: evidence from the United States since 1869. W.P. The School of Business, University of Wisconsin-Madison.

Bong-Soo, L., 1992. Causal relations among stock returns, interest rates, real activity and inf ation. J. Fin. 48, 1591-1603.

Campbell, J., 1990. Measuring the persistence of expected returns. AEA papers and proceedings, 43-47.

Campbell, J., 1993. Intertemporal asset pricing without consumption data. Am. Econ. Rev. 83, 487-512.

Campbell, J., Shiller, R., 1988. Stock prices, earnings and expected dividends. J. Fin. 43, 661-676.

Campbell, J., Shiller, R., 1989. The dividend price ratio and expectations of future dividends and discount factors. Rev. Fin. Stud. 1, 195-227.

Chen, N.F., 1991. Financial investment opportunities and the macroeconomy. J. Fin. 46, 529-554.

Cozier, B., Rahman, A., 1988. Stock returns, inf ation, and real activity in Canada. Canadian Journal of Economics 21, 758-774.

Epstein, L.G., Zin, S.E., 1989. Substitution, risk aversion, and the temporal behavior of consumption and asset returns: theoretical framework. Econometr. 57, 937-969. 
Fama, F., 1981. Stock returns, expected returns, real activity, inf ation and money. Am. Econ. Rev. 71, $546-565$.

Fama, F., 1990. Stock returns, expected returns and real activity. J. Fin. 45, 1089-1109.

Fama, F., French, 1988. Dividend yields and expected stock returns on stocks and bonds. J. Fin. Econ. $22,3-25$.

Gallinger, G.W., 1994. Causality test of the real stock return-real activity hypothesis. J. Fin. Res. 27, 273-288.

Grossman, S., Shiller, R., 1981. The determinants of the variability of stock market prices. Am. Econ. Rev. 71, 222-227.

Hawawini, G., Keim, D., 1994. On the predictability of common stock returns: world-wide evidence. WP Rodney L. White Center for Financial Research, 22.

Kandel, S., Stambaugh, R.F., 1991. Asset returns and intertemporal preferences. J. Mon. Econ. 27, 39-71.

Kimball, M.S., 1990. Precautionary saving in the small and in the large. Econometr. 58, 53-73.

LeRoy, S., Porter, R., 1981. The present value relation test based on implied variance bounds. Econometr. 49, 555-574.

Lucas, R., 1978. Asset prices in an exchange economy. Econometr. 46, 1429-1445.

Lee, K., 1996. Long-term output growth as a predictor of stock returns. Appl. Fin. Econ. 16, 412-432.

Malliaris, A.G., Urrutia, J.L., 1991. An empirical investigation among real, monetary and f nancial variables. Econ. Lett. 37, 151-158.

Marathe, A., Shawky, H., 1994. Predictability of stock returns and real output. Q. Rev. Econ. Fin. 34, 317-331.

Mehra, R., Prescott, E., 1985. The equity premium: a puzzle. J. Mon. Econ. 15, 145-161.

Peiró, A., 1996. Stock prices, production and interest rates: comparison of three European countries with the USA. Emp. Econ. 21, 221-234.

Restoy, F., Weil, P., 1998. Approximate equilibrium asset prices. W.P. NBER, No. 6611.

Schwarz, G., 1978. Estimating the dimension of a model. Ann. Statist. 6, 461-464.

Shiller, R., 1981. Do stock prices move too much to be justif ed by subsequent changes in dividends? Am. Econ. Rev. 71, 421-436.

Shiller, R., 1991. Market Volatility. MIT Press, Cambridge, MA.

Weil, P., 1989. The equity premium puzzle and the riskfree rate puzzle. J. Mon. Econ. 24, 401-421.

Weil, P., 1992. Equilibrium asset prices with undiversif able labor income risk. J. Econ. Dynam Control 16, 769-790.

West, K.D., 1988. Dividend innovations and stock price volatility. Econometr. 56, 37-61. 